\title{
Some Characteristics of the Referential and Inferential Predication in Classical Logic
}

Nijaz Ibrulj 1

\begin{abstract}
In the article we consider the relationship of traditional provisions of basic logical concepts and confront them with new and modern approaches to the same concepts. Logic is characterized in different ways when it is associated with syllogistics (referential - semantical model of logic) or with symbolic logic (inferential syntactical model of logic). This is not only a difference in the logical calculation of (1) concepts, (2) statements, and (3) predicates, but this difference also appears in the treatment of the calculative abilities of logical forms, the ontological-referential status of conceptual content and the inferential-categorical status of logical forms. The basic markers or basic ideas that separate ontologically oriented logic from categorically oriented logic are the (1) concept of truth, the (2) concept of meaning, the (3) concept of identity, and the (4) concept of predication. Here, this differences are explicitly demonstrated by the introduction of differential terminology. From this differential methodology follows a new set of characterizations of logic.
\end{abstract}

Key words: logic, calculus, syllogistics, symbolic logic, reference, inference

\footnotetext{
${ }^{1}$ N.Ibrulj

University of Sarajevo, Faculty of Philosophy, Dept. Of Philosophy

Franje Račkog 1, 71000 Sarajevo, Bosnia and Herzegovina

nijaz.ibrulj@ff.unsa.ba
} 


\section{Introduction}

The German philosopher Immanuel Kant thought that every logic is inferential and discursive (analytical a priori), but that not every logic is referential and semantical (synthetical a priory). Only logic that deals with the objects (Gegenstands) of thought which exists in the sensory world of experience, and not only with pure logical forms of thinking, is referential. Such kind of logic is transcendental logic whose basic motto is: "Gedanken ohne Inhalt sind leer, Anschauungen ohne Begriffe sind blind." ( Kant, 1976: 94-105)

The semantic synthesis of the a priori concepts of reason (Verstand) and the objects given in the experience is the main question of transcendental logic that was to be solved by transcendental deduction. But the main problem remains: how to perform semantic deduction of transcendental ideas of mind (Vernunft) and their synthesis with objects if ideas do not have sensory objects in experience... than in some other domain, in the domain of possible experience, in the domain of possible discourse and variable referentialism, i.e. in the domain of synthetic inferentialism based on transcendental apperception! Synthetic judgments a priori are not possible as a referential discourse of concepts but only as an inferential syntactic schematism based on formal equivalence or in the unconditional unity of concept and object provided by the imagination of the transcendental Self.

In his critical approach to ordinary (allgemeine) logic Kant has characterized Aristotle's syllogistic logic as non-referential logic, and his own transcendental logic as both inferential and referential logic. (Kant, 1976: 15) But is that so? Kant did not experience the development of symbolic and mathematical logic and could not define from this new point of view which logic is referential and which is inferential. Thus his transcendental logic as a "critique of pure reason" was considerably impoverished! From the standpoint of symbolic and mathematical logic, Aristotle's syllogistic logic was more referential, that is, inferential and referential at the same time!

There is a definition that reduces the whole of logical science (Wissenschaft der Logik, The Science of Logic) to the term "logic" which claims that "logic is the science of constructing a correct conclusion in the process of reasoning and valid proof in the process of proving". In addition, the "concepts", the "judgments", and the "conclusions" are defined as "forms of valid thought" that participate in construction of the "definitions" and the "proofs". On the other hand, logic, although a completely autonomous philosophical and scientific discipline, in its implementation, however, depends on two very important scientific fields: the 
science of language or "semiotics (syntax, semantics, pragmatics) " (Carnap, 1948: 89) as a way of expressing its forms and materialized in natural or artificial language, as well as from mathematical science (algebra, arithmetic, set theory and function theory) as a type of logical / mathematical operations performed on logical forms (Boole, 1854; Peano, 1889; Frege, 1879; Russell, 1900; Hilbert, 1930).

The above reduced definition of concept "logic" might be adequate if the overall mathematic science could be reduced to general algebra in the claim that "algebra is the science of the exact solution of mathematical problems" and if the overall linguistics could be reduced to grammar as "the science of correct sentence writing." Nevertheless, logic, mathematics, and linguistics entered into an alliance that gave rise to formal or logical semantics, formal or logical syntax, and formal or logical pragmatics that marked the arrival of an experimental philosophy and a scientific epistemology that then met in epistemological strategies of analytical philosophy and philosophy of science.

However, as mathematical and linguistic sciences, so the logical science is a complex, constructed and developed scientific discipline so that there is no short and unique definition of logic that would cover in one sentence all aspects of logical research, all the ways in which logic deals with its objects, and the possibility of logic itself being the subject of its research in metalogic! In addition, any systematic knowledge that is organized around a research subject and whose knowledge is obtained by applying some research tools must meet basic logical principles, must appear on the horizon of logic and be compatible with logic.

Every rationalized human action and automated action of artificial intelligence systems (automata, machines, expert systems, robotics) takes place under the action of the principle of the logical (Ibrulj, 1999, 187-214) which directs and orients it from within to achieve a certain goal which is a logical (algorithmic) consequence of previously undertaken actions and deeds or previously postulated claims. Furthermore, any description of mutually logically dependent events or happenings that stand in some, internal or external relation, tends to be made in some metalogic account. Because of all this, definition of logic should be gradually reached by stating preliminary characterizations of its field of research, its subject, its principles, i.e. its application, its vocabulary and role in scientific theories and philosophical systems.

Logic is the science that establishes laws and procedures of different complexity that correspond to objects of different complexity that are being investigated. In logic, norms and rules show how logical forms should be formed and transformed 
and logical operations applied to them, so that the result (consequences of formation and operation) has a true value, i.e. it is true or false. Logic is the scientific research of objects called logical forms or logical relations between parts of conceptual content, which is carried out in the field of linguistic-grammatical representations (symbols) of the mentioned objects and their relations. Logic is therefore a heuristic, descriptive and normative science that is not independent of ontological and epistemological assumptions and that cannot be fully defined without connecting all aspects of its theoretical and practical part. Logic can be said to be a science that deals

1) with characterizing the predicate "logical" for a given linguistic form of a statement that has at least one logical operational constant (and, or, no, if, if and only if,), or such statements that have either a form of negation or a form of conjunction, or a form of disjunction, or a form of implication (conditional), or a form of equivalence ( biconditional).

2) with characterizing the predicate "true" for a given linguistic form of statement that has at least one logical constant and at least one variable $(F(x))$, or such a form of statement that contains one or more truth-values,

3) with the research, description and revision of conceptual scheme, logical and grammatical categories (epistemological aspect, descriptive metaphysics);

4) with the origin and application of the form of valid thought (critical aspect);

5) with the semantic and syntactic structure of logical systems (linguisticgrammatical aspect);

6) with the type and existence of the entities to which the symbolic notation refers (formal-ontological aspect, formal-semantic aspect);

7) with discovering the basic laws of thought, their application in the process of formalization in the substitutional and quantification form of speech (methodological-deductive aspect);

8) with verifying the views of non-philosophical sciences (methodologicalinductive aspect); 
9) with the contextual analysis of the use of symbolic systems (pragmaticsemiotic aspect),

10) with translating the idiom of natural languages into the canonical notation of artificial languages.

Therefore, from the above, it is shown that logic for its subject has not only valid forms of thought and their application, but also deal with ontological and epistemological assumptions (Dewey,1938), or with inferential, referential and pragmatical models of the logical pragmatism in epistemological strategies of philosophy and science (Ibrulj, 1999).

\section{Logic as a Calculus with Words in Natural Language}

The traditional approach to logic starts from the fact that logic is exclusively a philosophical discipline that deals with the correct conclusion, i.e. research of the form of valid thought and their application in the process of forming evidence of arguments. As a philosophical discipline, logic is today reduced exclusively to calculus, to the so-called formal monotonic logic as the basis of formal argumentation in the medium of natural languages (soft computing, computing with words, fuzzy logic) or to formal symbolic logic in the medium of the languages of symbolic notation (crisp logic).

The development of epistemology and cognitive science (cognitive psychology, computational linguistics, computational science, informatics), and the development of multivalued logic (Łukasiewicz, 1963), modal logic (Kripke,1972), fuzzy logic (Zadeh, 1968), logical programming, computing with words (Zadeh, 1987) and soft computing, these scientific disciplines have taken over scientific research and explanation of cognitive processes, construction the procedure of defining objects (entities) in homogenized and hybrid contexts (Rieger, 1999) and therefore largely defining the functioning of logical and linguistic competence in humans.

Now the rational and linguistic competence of intelligent systems (animals, humans and machines) is studied experimentally in connection with neurobiological processes ( John R. Searle, Patricia Churchland), mental activities and their ability to manipulate symbols (Jerry Fodor, Paul Churchland), and not only through introspective and hermeneutic insights of man.

The traditional approach to logic can be called a dichotomous approach because the existence of an object or entity of cognition (subject content and subject form) is 
taken as completely independent and separated from their conceptual or intellectual existence (logical content and logical form) as well as their linguistic representation (linguistic content and linguistic form). This approach has created basic dichotomous categories of traditional logic and traditional epistemology such as substance vs. accident, subject vs. predicate, form vs. content, apriroy vs. a posteriori, analytic vs. synthetic, empirical vs. transcendental, particular vs. universal.

The understanding of logic created on these dichotomies was a consequence of the close connection between logic and metaphysics in the pre-Socratic, Platonic and Aristotelian traditions. Logic was understood here as tool (organon) of deduction from the principles set by metaphysics and about which logic could say nothing. Metaphysics was in charge of finding principles, especially the first principles and the first causes (Aristotle, M. 982 a 33), and logic was only in charge of deduction or derivation from such true principles. That is why metaphysics was the first philosophy, physics the second philosophy ... and logic itself was only an organon or an instrument of deduction and derivation that uses logical laws and rules (Aristotle, Prior and Posterior Analytics).

Metaphysics also included the proof science (analytics, syllogistics, apodictics) which dealt with the logical (formal) causes of the truth of propositions, while metaphysics as the "first philosophy" provided all scientific fields with knowledge of the first causes and first principles of being, i.e. knowledge of being as being ( $\tau \dot{o}$ óv $\dot{\eta}$ óv ) (Being).(Aristotle, M. 1003 a 21). Ontology as onto-theology set the being (what is) and its structure, and it remained for logic to correctly map that structure into its categories / structures with the help of concepts and terms (Aristotle, Categories). The metaphysical concept proceeded from the system of the veritative being that is, from the connection and mutual conditioning of true expression and necessary existence. In this system of veritative being, the theory of truth and the theory of the meaning of essentialist logic are expressed: in one statement, "true statement" that something belongs to something means "necessarily being" in reality that way; and "necessarily to be" in reality so-and-so means "to true statement" that it is soand-so. This concept of logic includes the definition of the concept as a valid thought about the essence of what is being thought about.

Necessary or accidental existence of object and its properties is expressed in traditional logic as a necessary or accidental affiliation of predicates to one subject, or as a necessary (synonymous) or accidental (homonymous) prediction (affirmation or denial) of a property to a subject (Aristotle, Categories). So the dichotomy between what is necessary (what exists by itself) and what is accidental (what 
exists by something or because of something else), which is set as an ontological difference between the being as being and singular being, is then carried out in both the conceptual and linguistic plane of cognition. Traditional logic is an integral part of traditional (essentialist, metaphysical) epistemology in which the central concept is the logical foundation or logical justification of true knowledge or cognition. In this concept, the truth of a thought or statement can be established if its logical justification can be found, i.e. if it is possible to find a set of true thoughts or statements from which, by applying logical rules of inference, the claims or thoughts in question can be derived. The proof consists in the formation of a chain of connected claims that logically follow from each other and into which nothing sensual, i.e. no experience and nothing individual, enters.

The definition of a subject in the traditional approach to logic is essentialist. A definition is a judgment that determines the content of a concept (notion), that is, gives an answer to the question of what something is ( $\tau i$ ह่ $\sigma \tau \iota \nu$ ) or what is the essence of something. At the same time, this means that the object has some

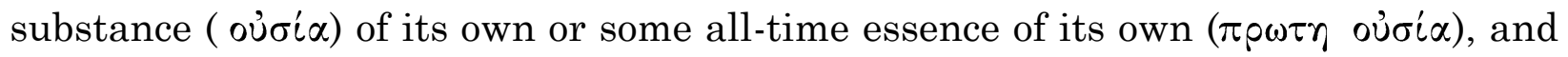
that the meaning of the word just communicates or expresses that essence. This connection between the object, its concept and the meaning of the word in use has led to semantic paradoxes such as the liar: when a Cretan says: "All Cretans lie" then that judgment is true and false at the same time.

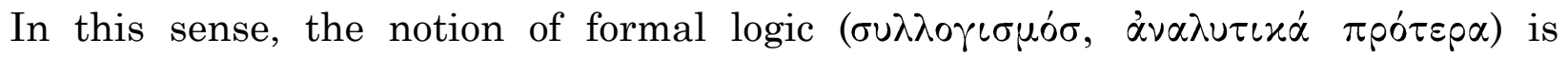
conditioned by the understanding of the relationship of parts of the thought content expressed in natural language. This relationship is established as a relation of that part of the thought content which precedes (antecedents) and that part which follows (consequent) and which stand in a cause-and-effect relationship. This relationship implies the construction, reconstruction or deconstruction of parts of the thought content according to the logical relationship that can be established between them: as a subsumption of objects under a concept or as a subordination of a subordinate concept under a concept of a wider scope.

In this sense, formal logic can be defined as a formal (from the given form of conceptual content) relationship of some content whose parts can be divided into some units that have different levels of logical generality: narrowest (individual, óv,

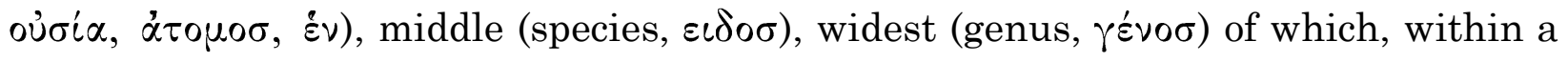

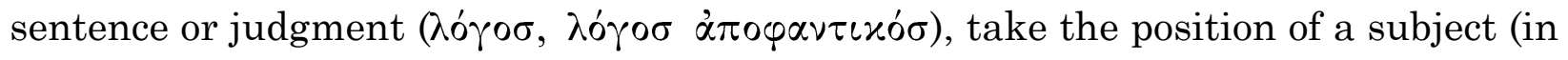
linguistic predication) or a subject (in logical predication) or a substrate / substance (in metaphysical predication).Because there are formal rules of composition of this content that apply to any content and which due to their application can lead to the 
truth of the statement, this type of truth obtained on the basis of valid manipulation of parts of the content is called logical or formal truth.

\section{Partial Formalization of the Logic: Syllogistic Logic}

The syllogistic system of inference ( $\sigma \cup \lambda \lambda \circ \gamma\llcorner\sigma \mu o ́ \sigma)$ and proof $(\dot{\alpha} \pi \circ \delta\llcorner\varkappa \tau \iota \varkappa \dot{\eta})$ is an Aristotelian formalized system based on

(1) Formal-logical principles or laws of thought

(2) Formal-logical differentiation of the concept of identity

(3) Predicative schematism of concepts that form the structure of judgment.

(4) A quantified scheme of logical predication

(5) The logical relations of subsumption and subordination

(6) Logical operations of affirmation and negation

(7) Logical schematism of predication

Formal logical principles ( $\alpha \rho \chi \dot{\eta})$ or laws of thought are the standards or rules of formation and use of thought forms in their intuitive-practical and scientifictheoretical application either in natural language or in artificial language. The purpose of the application of logical laws or laws of thought is the consistent noncontradictory formulation of simple and complex thoughts in affirmative or negative form and the homologation of predicates in relation to a given subject of statement.

Logical laws are not laws of nature (Frege). Logical principles or laws of thought are logical truths or logical rules, or logical generalizations by which or in accordance with which is possible to

(1) deduce a valid and correct inference, that is

(2) deduce the conclusion (drawing conclusions from the given premises),

(3) draw correct, valid and true conclusions.

By logical principles or laws of thought, different authors meant different things (different objects), but in the traditional sense, there are four laws of thought 
- (PID) principle or law of identity, symbolically expressed in traditional logic $\mathrm{A}=\mathrm{A}$ or $\mathrm{A}$ is $\mathrm{A}$; in the notation of modern logic the corresponding symbol is $\mathrm{p}$ $\equiv \mathrm{p}$

- (PC, PNC), principle of contradiction (or: the principle of non-contradiction); in modern logical notation $\neg(\mathrm{p} \wedge \neg \mathrm{p})$.

- (PEXM, PEXT) principle of exclusion of middle or third; in modern logical notation the formula $\mathrm{p} v \neg \mathrm{p}$.

- (PSR) principle of sufficient reason.

Logical principles or logical laws are static generalizations or constructive schemes of thought processes of comprehension, judgment, inference, such as natural laws of static generalization of natural processes in space and time. It is reasonable to ask a questions: Are there any changes in logic at all ? Are new standards possible? Whether the laws of logic change or only the ways of their application or only the ways of their notation.

Characterization of logical principles is done according to the area of their application and according to the objects to which they are applied, which can be existent entities and virtual (subsistent) entities. The following characterizations should be stated: (1) in the ontological sense, (2) in the formal logical sense, (3) in the epistemological sense, (4) in the linguistic-grammatical sense, (5) in the logicalmathematical sense.

The formal-logical differentiation of the concept of identity in syllogistic logic is based on the distinction and combinatorics of the three concepts of identity that establish different predicate schemes (synonymous predication, homonymous predication and paronymous predication).

IDENTITY (type-1) in the sense to be of the SAME-GENUS (things that belong to the same genus, that is, they have the SAME ESSENCE: $\check{\omega} \nu \mu i \alpha \dot{\eta}$ ov $\sigma^{\prime}(\alpha)$ (Aristotle, M.1021 a10). According to this concept of identity in the predication scheme, subject and predicate are synonymous things, i.e. they have a common name (name of the genus to which they belong) and therefore have the same definition (the same notion of essence marked by name, because genus is the notion and essence of these things). All beings belonging to the genus of living beings have a common name: "animals", and every being that is a living being has the same definition of "living" or the same notion of living in its provision. This does not mean that they are physically identical beings (e.g. man and ox). 
IDENTITY (type-2) in the sense to be of the SAME-SPECIES (things that belong to the same species, that is, they have the SAME QUALITY OF ESSENCE: $\tilde{\omega} v \dot{\eta}$ $\pi$ có$\left.^{\prime} \eta \sigma \mu \mu^{\prime} \alpha\right)$. According to this concept of identity in the predication scheme, the subject and the predicate are only the homonymous things, i.e. they have only the same species name, they do not belong to the same genus, and they have a different definition.

IDENTITY (type-3) in the sense to be of the SAME - NUMBER (things that have

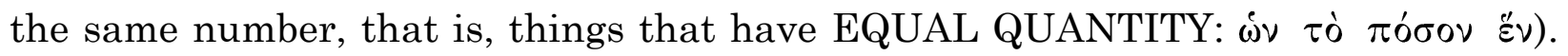
According to this concept of identity in the predication scheme, the subject and the predicate are only the things which are identical in number.

Logical operations within such types of predication have different logical operations from the point of view of their apophantic form: propositions that are apophantic affirmations or apophantic negations of the relationship of subject and predicate are logically necessary consequences in a synonymous predication, while those in homonymous predication are probable or accidental consequences.

Logical Relations of Subsumption and Subordination. Subsumption (falling of an object under a concept, inclusion of an individual object in a type or class) is a logical operation of bringing or falling (inclusion) of an individual object under a concept. Subordination (subordination of a concept under a superior concept, generation of subordinate genus and species) is a logical operation of subordination (inclusion) of one concept under a superior higher concept. Here, logical operation is determined by the relationship between a narrower and a broader concept, i.e. the concept of a lower degree of logical generality and the concept of a higher degree of logical generality.

Logical operations of affirmation and negation. Affirmation (confirmation,

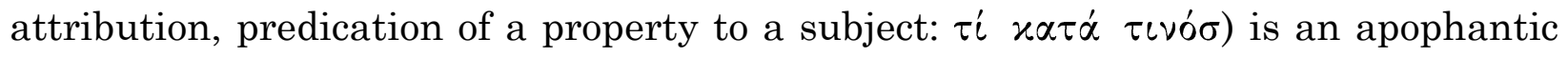
form of pronouncing or affirming the affiliation of a property to one subject in whole or in part. Negation (denial of a property to a subject, denial of belonging to a subject, $\left.\tau \dot{i} \alpha \dot{\alpha} \delta^{\prime} \tau \iota v o ́ \sigma\right)$ is an apophatic form of denial or denial of a property to a subject in whole or in part.

Logical schematism of predication. The syllogistic concept of truth and validity of the conclusion is based on the predicative scheme and its models of the relationship between the subject and the properties of the first order, the predicate in the role of the subject and the second order predicate, or analogous schemes of 
paronymy. The type of syllogistic schematism depends on the type of identity by which one predication is formulated. There are three basic predicative schemes within the syllogistic system of formalizations that allow inference and proof

Syllogistic logic is determined by the predicative form of judgment and inference. Synonymous and homonymous predication differ in categorical and intercategorical predicative schematism (Aristotle, Categories, 1a 1-15). Synonymous predication is a vertical and continuous or subordination-determined predication of subordinate and superior predicates (species and genera) which are pronounced as predicates to all subordinate entities / genera, species, individual beings. Homonymous predication is a horizontal and discontinuous predication or subsumption of entities from different categories where predicates, genders and species are combined that do not fall under each other, but are properties and differences that are random members of a subject or random properties of a subject. Paronymous predication is a predication by analogy between things: according to the term for the property of bravery, a man received the predicate brave, according to the term grammar, someone was called a grammarian, according to the term philosophy, someone was called a philosopher.

\section{Syllogistics in Figures of the Components of Judgements: Calculus of Terms (Concepts)}

The logico-linguistic apparatus of syllogism or indirect deductive inference in the schematism allowed by natural language is set out in Aristotle's work "First

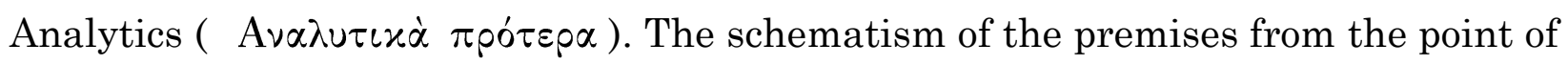
view of quantity (major and minor) depends on their degree of logical generality: one is always universal. Schematism of the premises from the point of view of the arrangement of terms: the premises contain three terms, two of which are predicates (genus, species) and one is an individual term. The notion of species ( $(\tilde{i} \delta \circ \sigma)$ is the middle notion: it is the cause of the truth of the conclusion (Aristotle)!

\section{Elements of syllogistic structure (judgements)}

MP - the Major Premise of the conclusion or U - PREMISE (universal P)

$\mathrm{mP}$ - the minor Premise of the conclusion or P - PREMISE (particular P)

$\mathrm{C}$ - Conclusion; logical result of calculus; logical score 


\section{Elements of structure of syllogistic premises (terms, concepts)}

S $\quad$ [subject / minor term]:

TERM 1.

M [predicate $-1 /$ middle term]: TERM 2.

$\mathrm{P} \quad$ [predicate $-2 /$ major term]: TERM 3.

The table below, known as the syllogism figure, shows the relationships of the three terms in the syllogism, which are arranged in two premises and a conclusion. The notion of subject (minor term) is narrower in scope than the notion that first encompasses it in the system of provisions (middle term), and this is narrower in scope than the notion that the second encompasses it in the system of provisions (major term). The subject is always defined with two terms that have a wider range than it: the minor (first) predicate and the major (second) predicate. This scheme is the complete structure of the predicate model of deduction in Aristotle's logic.

Aristotle's key to interpreting the predicate scheme in a syllogism is a mode that shows how one term is contained in another term that encompasses it: (1) as a part of the whole that generically (vertically) encompasses it below itself, (2) as a whole as a whole

The second key to the interpretation of the predicate scheme in the syllogism is the mode of identity on which the predicate scheme is constructed: (1) (2) (3)

Minor Term

(S) = Subject of Conclusion

$\mathrm{T} 1$

Middle Term

$(\mathrm{M})=$ Term that occurs in both premises

T 2

Major Term

$(\mathrm{P})=$ Predicate of Conclusion

T 3

\begin{tabular}{l|cc|cc|cc|cc} 
& \multicolumn{2}{|c|}{ I. } & \multicolumn{2}{|c|}{ II. } & \multicolumn{2}{|c|}{ III. } & \multicolumn{2}{|c}{ IV. } \\
\hline Major Premise & M & P & P & M & M & P & P & M \\
Minor Premise & S & M & S & M & M & S & M & S \\
\hline Conclusion & S & P & S & P & S & P & S & P
\end{tabular}


The table below shows the relationships of three terms of different levels of logical generality or three terms of different scope. The sign < indicates that the term on the left is a lower level of logical origin than the term on the right of the sign.

A term that has a lower level of logical generality is included in a term that has a higher level of logical generality.

The general scheme of the relationship of these three terms is as follows:

$\mathrm{T} 1<\mathrm{T} 2<\mathrm{T} 3>\mathrm{T} 2>\mathrm{T} 1$.

\begin{tabular}{c|c|c|c|c|c} 
& I. & II. & III. & IV. \\
\hline & & & & & \\
Major Premise & $\mathrm{T} 2$ & $<\mathrm{T} 3$ & $\mathrm{~T} 3<\mathrm{T} 2$ & $\mathrm{~T} 2<\mathrm{T} 3$ & $\mathrm{~T} 3 \quad>\mathrm{T} 2$ \\
minor Premise & $\mathrm{T} 1<\mathrm{T} 2$ & $\mathrm{~T} 1<\mathrm{T} 2$ & $\mathrm{~T} 2 \quad>\mathrm{T} 1$ & $\mathrm{~T} 2 \quad>\mathrm{T} 1$ \\
\hline Conclusion & $\mathrm{T} 1<\mathrm{T} 3$ & $\mathrm{~T} 1<\mathrm{T} 3$ & $\mathrm{~T} 1<\mathrm{T} 3$ & $\mathrm{~T} 1<\mathrm{T} 3$
\end{tabular}




\section{Two Translations of Syllogistic Figures in the Form of "Aristotle's Sudoku"}

$$
\begin{array}{ccccc}
1 & 2 & 3 & 2 & 1 \\
\mathrm{~S} & \mathrm{M}< & \mathrm{P}>\mathrm{M}>\mathrm{S}
\end{array}
$$

\begin{tabular}{|c|c|c|c|c|c|c|}
\hline I.F & Barbara & Celarent & Darii & Ferio & & \\
\hline MP & $\mathrm{M}>\mathrm{S}$ & $\mathrm{M}>\mathrm{S}$ & $\mathrm{M}>\mathrm{S}$ & $\mathrm{M}>\mathrm{S}$ & & \\
\hline $\mathrm{mP}$ & $\mathrm{P}>\mathrm{M}$ & $\mathrm{P}>\mathrm{M}$ & $\mathrm{P}>\mathrm{M}$ & $\mathrm{P}>\mathrm{M}$ & & \\
\hline $\mathrm{C}$ & $\mathrm{S}<\mathrm{P}$ & $\mathrm{S}<\mathrm{P}$ & $\mathrm{S}<\mathrm{P}$ & $\mathrm{S}<\mathrm{P}$ & & \\
\hline II.F & Cesare & Camestres & Festino & Baroco & & \\
\hline MP & $\mathrm{P}>\mathrm{M}$ & $\mathrm{P}>\mathrm{M}$ & $\mathrm{P}>\mathrm{M}$ & $\mathrm{P}>\mathrm{M}$ & & \\
\hline $\mathrm{mP}$ & $\mathrm{S}<\mathrm{M}$ & $\mathrm{S}<\mathrm{M}$ & $\mathrm{S}<\mathrm{M}$ & $\mathrm{S}<\mathrm{M}$ & & \\
\hline $\mathrm{C}$ & $\mathrm{S}<\mathrm{P}$ & $\mathrm{S}<\mathrm{P}$ & $\mathrm{S}<\mathrm{P}$ & $\mathrm{S}<\mathrm{P}$ & & \\
\hline III.F & Darapti & Datisi & Disamis & Felapton & Ferison & Bocardo \\
\hline $\mathrm{MP}$ & $\mathrm{M}<\mathrm{P}$ & $\mathrm{M}<\mathrm{P}$ & $\mathrm{M}<\mathrm{P}$ & $\mathrm{M}<\mathrm{P}$ & $\mathrm{M}<\mathrm{P}$ & $\mathrm{M}<\mathrm{P}$ \\
\hline $\mathrm{mP}$ & $\mathrm{M}>\mathrm{S}$ & $\mathrm{M}>\mathrm{S}$ & $\mathrm{M}>\mathrm{S}$ & $\mathrm{M}>\mathrm{S}$ & $\mathrm{M}>\mathrm{S}$ & $\mathrm{M}>\mathrm{S}$ \\
\hline $\mathrm{C}$ & $\mathrm{S}<\mathrm{P}$ & $\mathrm{S}<\mathrm{P}$ & $\mathrm{S}<\mathrm{P}$ & $\mathrm{S}<\mathrm{P}$ & $\mathrm{S}<\mathrm{P}$ & $\mathrm{S}<\mathrm{P}$ \\
\hline IV.F & Bramantip & Camenes & Dimaris & Fesapo & Fresison & \\
\hline $\mathrm{MP}$ & $\mathrm{P}>\mathrm{M}$ & $\mathrm{P}>\mathrm{M}$ & $\mathrm{P}>\mathrm{M}$ & $\mathrm{P}>\mathrm{M}$ & $\mathrm{P}>\mathrm{M}$ & \\
\hline $\mathrm{mP}$ & $\mathrm{M}>\mathrm{S}$ & $\mathrm{M}>\mathrm{S}$ & $\mathrm{M}>\mathrm{S}$ & $\mathrm{M}>\mathrm{S}$ & $\mathrm{M}>\mathrm{S}$ & \\
\hline $\bar{C}$ & $\mathrm{~S}<\mathrm{P}$ & $\mathrm{S}<\mathrm{P}$ & $\mathrm{S}<\mathrm{P}$ & $\mathrm{S}<\mathrm{P}$ & $\mathrm{S}<\mathrm{P}$ & \\
\hline
\end{tabular}

Here it is clearly shown how the terms in the premises of the syllogism and in the conclusion relate from the point of view of the logical relations of inclusion and exclusion into each other, ie from the point of view of the logical relations of subsumption and subordination. 


$$
\begin{aligned}
& \mathrm{S}<\mathrm{M}<\mathrm{P}>\mathrm{M}>\mathrm{S} \\
& \mathrm{T} 1<\mathrm{T} 2<\mathrm{T} 3>\mathrm{T} 2>\mathrm{T} 1
\end{aligned}
$$

\begin{tabular}{|c|c|c|c|c|c|c|}
\hline I.F & Barbara & Celarent & Darii & Ferio & & \\
\hline MP & $2>1$ & $2>1$ & $2>1$ & $2>1$ & & \\
\hline $\mathrm{mP}$ & $3>2$ & $3>2$ & $3>2$ & $3>2$ & & \\
\hline $\mathrm{C}$ & $1<3$ & $1<3$ & $1<3$ & $1<3$ & & \\
\hline II.F & Cesare & Camestres & Festino & Baroco & & \\
\hline MP & $3>2$ & $3>2$ & $3>2$ & $3>2$ & & \\
\hline $\mathrm{mP}$ & $1<2$ & $1<2$ & $1<2$ & $1<2$ & & \\
\hline $\mathrm{C}$ & $1<3$ & $1<3$ & $1<3$ & $1<3$ & & \\
\hline III.F & Darapti & Datisi & Disamis & Felapton & Ferison & Bocardo \\
\hline MP & $2<3$ & $2<3$ & $2<3$ & $2<3$ & $2<3$ & $2<3$ \\
\hline $\mathrm{mP}$ & $2>1$ & $2>1$ & $2>1$ & $2>1$ & $2>1$ & $2>1$ \\
\hline $\mathrm{C}$ & $1<3$ & $1<3$ & $1<3$ & $1<3$ & $1<3$ & $1<3$ \\
\hline IV.F & Bramantip & Camenes & Dimaris & Fesapo & Fresison & \\
\hline MP & $3>2$ & $3>2$ & $3>2$ & $3>2$ & $3>2$ & \\
\hline $\mathrm{mP}$ & $2>1$ & $2>1$ & $2>1$ & $2>1$ & $2>1$ & \\
\hline $\mathrm{C}$ & $1<3$ & $1<3$ & $1<3$ & $1<3$ & $1<3$ & \\
\hline
\end{tabular}

The traditional interpretation of these figures is based on their schematism of the relationship between subject and predicate in two premises and one conclusion in which according to the form of the figure three notions of different logical generality (genus, species, individual notion) are arranged in the relations of subsumption and subordination.

The middle level of logical generality is the notion of a species that mediates between the notion of genus and the individual notion: a species is encompassed by 
a genus and is given all the properties of a genus, and it encompasses individually and determines it.

The roles that these three terms have in judgement are marked by the positions they can take as terms

Minor Term $\quad(\mathrm{S})=$ Subject of Conclusion

Middle Term $\quad(\mathrm{M})=$ Term that occurs in both premises

Major Term $\quad(\mathrm{P})=$ Predicate of Conclusion

The position of the middle term is decisive for deduction, because, as Aristotle states in every conclusion, the middle term is the cause of the truthfulness of the judgement. In courts that are premises, all terms (major, middle, minor) can have all the roles, be in the position of both subject and predicate. Only a minor term and a major term can be in the conclusion, and that is strictly a minor term in the position of a subject of the judgement and a major term in the position of a judgement predicate. The middle term does not appear in the conclusion.

Aristotle's key for the construction of the mode of syllogism. It is made from the relationship of parts of statements that have calculative logical properties: the logical degree of generality (genus, species, individual, species property, property of the individual) in the role of subject or predicate; logical relations of subsumption and subordination of concepts, from logical operations of affirmation and negation. By applying these elements of the syllogism, the figures and modes of the syllogism are constructed

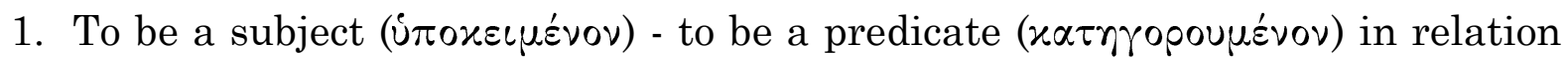
of SUBSUMITION

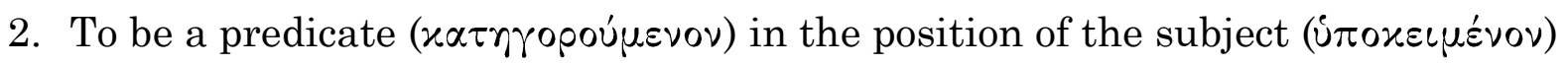
in relation of SUBORDINATION

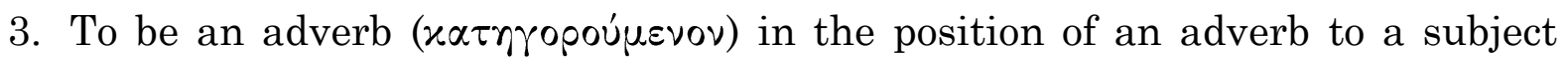

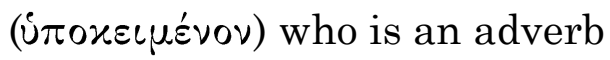

4. To be contained in the subject - to be expressed about the subject

5. To be individual - to be a species, to be genus, to be a difference

6. To be a genus that is below the genus (differences of vertical genera)

7. To be a genus that is not a position below a genus (differences of horizontal genus) 
Rules for interpretation by the form of predicate scheme. To be a mode of syllogism that has the structure of a synonymous predication (serial-vertical predication - generic predication - homologization); necessary belonging - definition. To be a mode of syllogism that has the structure of a homonymous predication (parallel. Horizontal predication); accidentally belonging to the subject - division of the genus into species.

\section{Complete Formalization of the Logic: Symbolic Logic}

The modern approach to logic starts from the fact that logic is a scientific discipline that is identical to mathematics (Boole, Peano, Frege, Russell) because of its procedures and laws, and more recently that logic is identical to the pure logical syntax of language (Carnap,1937: p. xiii ) of artificial (symbolic) language that allows computer logic programming procedures and their application.

Accordingly, mathematics, which is based on axiomatization systems (Hilbert, 1930), is actually only a more developed logic, that is, the whole mathematics can be reduced to a few basic logical laws (Russell, 1905) or to several logical procedures (algorithms). Since every natural science, when it reaches a certain level of knowledge about its subject, necessarily sets the principled or axiomatic basis as the starting point of its further knowledge (Hilbert, 1970:156), so every science necessarily requires logic as its syntax or as its (scientific) language (Carnap, 1937: xiii).

In the modern approach to logic, a term is taken as a symbol (simple or complex), a judgment or statement is taken as a function (Frege, 1879), truth is seen as the truth value of one statement or one set of related claims, proof is taken as a formal system, algorithm or system of procedures, validity is taken as the consistency of a set of statements, truth of propositions as its coherence.

At the same time, this approach is based on scientific research of logical procedures for solving problems, making the right decisions, making the right choice. Logical syntax is taken as the language of science (Carnap, 1937), that is, one artificial language (symbolically) is taken as a tool for expressing multiplied logical generality, and the logical operations that prevail between representations of these logical objects become a large part of mathematical derivation. It is therefore necessary that the correct definition of logic in addition to philosophical contains a scientific characterization. 
This approach to logic can be called a unifying or non-dichotomous approach, i.e. an approach that connects and connects formal logic and formal semantics and thus enables the production of formal-logical entities or a formal ontology from whose interpretation semantic paradoxes disappear.

Thus, the distinction between objects, concepts and terms lost its meaning and passed into the research of semantic and structural properties of formal deductive and inductive systems.

Thus the theory of natural classes, fundamental to the metaphysical concept of logic and to the formulation of logical categories, and the theory of sets, fundamental to the symbolic and mathematical concept of logic and to the formulation of transcendental categories replaced by the theory of virtual classes which became fundamental to the computer or computer concept of logic. This process brought about the transition of the interpretation of formal systems from an object-bound variable to a substitutive interpretation of a variable as a virtual class. (Quine, 1986: 72).

The modern approach to logic understands formal logic as the unity of formal semantics and formal ontology as it explores proper inference and valid proof through formalizations of whole statements (systems of symbolic representation) rather than just terms as in traditional logic (Frege, Russell, Wittgenstein).

A new or mathematical (symbolic) logic was created by Gottlob Frege's work on theidea of Begriffsschrift (concept letter), the discovery of the account of statements and the account of predicates, and the treatment of statements as functions. Bertrand Russell, Ludwig Wittgenstein, Rudolf Carnap, Alfred Tarski, and more recently Willard Van Orman Quine have made important contributions to the development of mathematical logic.

This concept of logic is an integral part of a different epistemology or naturalistic epistemology. Within this epistemology, the truth of a thought or assertion is grounded if it is possible to find in a (past) experience of a thing or fact or process a justified belief that must stand in connection with a network of beliefs that have the same logical form (because they always connect causes and consequences in the same way in the knowledge of an object, property, fact, state of affairs).

The definition of the subject in the modern approach to logic is functionalist. A definition is a judgment that determines the use of a concept. The definition provides an answer to the question of how something works or how it works in an empirical environment and in connection with other empirical concepts. 
In connection with this definition of the concept, a different definition of the meaning of a word has been developed: "the meaning of a word is its use in the language". (Wittgenstein, 2009, p.25e §43). Modern (symbolic or mathematical) logic as a way of avoiding and solving semantic paradoxes that arise in object language has developed formalized systems of interpretation, translation and paraphrase of object language expressions in meta-language expressions.

In this way, hierarchies of formalization emerged as a relationship of pure and descriptive syntax in which the logical and the linguistic and the ontological are harmonized at different levels of their generality, i.e. at different levels of formalized systems that translate variables into constants and open expression schemes or expression functions. into statements that have meaning and significance (truth value).

Logical ability is the formal ability and skill of manipulating with symbolic structures that represent parts of the logical content of one thought or one complex whole of conceptual content. This formal ability in use is referred to as logical calculus or calculation by logical forms. Conclusions and proofs are viewed as a valid calculation or calculation by symbolic representations (symbols, notation, signs) of conceptual content, i.e. as a construction of logical functions based on law and application of logical rules of establishing relations between parts of thought (concepts) and whole thoughts (judgments, statements).

Each logical form is determined by its capacity for logical functioning within the whole of a calculative procedure (calculations, computations, inferences, inferential transformations). A logically valid form of opinion (concept, judgment, conclusion, proof) is a logical form that has the following properties:

1. One-meaning

2. Truth value

3. Ability to integrate

4. Ability to distribute

5. A certain degree of logical generality

6. Translatability into another logical form by retaining the truth value

7. Assumption and interchangeability of the role of the subject or predicate

8. Ability of formal construction, reconstruction and deconstruction (formation, transformation, expansion and reduction) 
Logical function as a general form of predication. In syllogistic logic, the main role in the conclusion and proof was played by the judgment (logos apofantikos) which affirms or denies the fact that one property belongs to one subject. The quantity and quality of the premise, the place and position of the subject and the predicate in the premises determined the formal derivation of the conclusion. But the deduction was determined in advance by the quantity and quality of the premise that determined the positions of the terms in them and their logical relations.

From the beginning, symbolic logic removed judgments and their subject-predicate structure from the logical calculus and replaced it with the mathematical form of statements as a logical function that has an argument and a predicative part that are equally subject to quantification and determination of their semantic and syntactic properties.

The reduction of logical statements in symbolic logic has turned judgments into logical functions that are themselves a symbolic representation or construction composed of symbols that have their positions and roles (constants or variables) and operational properties (logical constants). Thus, all referential or semantic properties disappeared from the logical calculus and the syntactic and structural properties of symbols and logical operations came to the fore, ie the inferential construction of the whole of conceptual content, its possibility of translating or reconstructing into other symbolic formulas using other logical operations (expressing disjunction by conjunction and negation and expressing conjunction by disjunction and negation,....).

Thus, the predicative form was no longer semantic but syntactic, it was no longer based on subordination and subsumption but on the calculable properties of symbols and their representation, which introduced procedures for determining (granulation or unification) of logical variables by their quantification in atomic or complex logical functions. The predicative form in symbolic logic is a logical function through which the calculus of statements, the calculus of predicates, the calculus of classes, the calculus of relations are carried out.

Equivalence of logical formulas as a concept of identity in symbolic logic. Symbolic logic drastically changed the concept of identity and the concept of predication based on it from Aristotelian generic identity and synonymous predication based on the genus and species properties into a syntactic concept of identity that enabled logical identity as syntactic equivalence or as a tautology of symbols. Thus, genus, species and individual identity as a semantical (referential) 
relation between things or beings and words disappeared from the logical calculus, and identity as the equivalence of symbols ( $x$ means the same as $y$ ) were introduced into the logical calculus, which in different ways denote the same conceptual content or its sequences which by their logical structure provide evidence without reference to empirical givens.

Symbolic (mathematical) logic has enabled the development of artificial intelligence, ie the development of artificial languages and the automation of deductive systems, making it the main instrument of modern technology based on logical programming.

Truth-value as the meaning of symbols. What counts in the symbolic logic is not the meaning of words because the words of natural language are reduced to symbols, that is, whole sentences are represented by symbols. The only meaning of symbols is what is attributed to them in the process of deduction: that they are true or false, that symbols are therefore representatives of the true values of the statements they stand for. Their truth values of ptopositions represented by symbols are what is calculated or computed in formal symbolic logic, and the factual or material truth of the statements that the symbols represent is not determined by logic but by exact emoirical sciences.

\section{Extended Characterizations of the Logic}

According to Scholz (1961:172) there are several very important characteristics of symbolic (mathematical) logic as formal logic that distinguish it from other types of formal logic such as Aristotelian syllogistics or Stoic propositional logic. Here we will briefly paraphrase them.

1) Symbolic logic is the first stylistically pure type of formal logic that deals exclusively with pure forms free from any psychological contents of consciousness.

2) Symbolic logic is the first exact formal logic that is

a) precisely defined its axiomatic material so as to coincide with the precision and clarity of the axioms of mathematics;

b) the first logic that clearly defined the rules by which the propositions and concepts derived from axioms are obtained,

c) by applying symbols her propositions are as precise as those of mathematics; 
d) unlike non-symbolic formal logics that are able to formulate their statements, symbolic logic is able to formalize statements;

e) is able to formulate non-Aristotelian syllogistic rules by symbolic notation;

f) is able to explain what is happening in the judgements silogisation procedure;

d) the first is a formal logic that is able to accurately analyze the role of copula in different types of statements from the point of view of applying the rules of reasoning;

h) is the first formal logic that gave an exact analysis of existence that can be a predicate of an individual object, express the existence of properties and the existence of relations;

3) Symbolic logic is the first formal logic that was developed strictly synthetically, ie the first type of logic that developed methodically from a simple to a complex form;

4) Symbolic logic is the first perfect formal logic, ie the first logic that gave us complete inferential rules that are necessary for the development of modern mathematics;

5) Symbolic logic is the first experimental logic, i.e. the first logic that investigated systems of syllogistic rules that are not identical with Aristotle's;

6) Symbolic logic has freed us from psychologism, ontologism, the portage of evidence-based evidence;

7) Symbolic logic analyzed precisely the exemplary techniques of negation and created forms of statements in which negation refers accurately and precisely to the element of the statement that is being denied.

When all that has been said about the broadly branched science of logic and about formal logic, which is only a reduced part of it, is taken into account, then only some preliminary characterizations of the notion of logic can be given. "Logic", taken in the context of logical science, is a term with multiple meanings (Ibrulj, 2005) that characterizes

(i) intuitive ability to properly use thought forms laid down in natural languages and intuitive ability to adjust the semantic properties of natural languages and 
thought contents with appropriate logical sentence structures that have the character of material implications made in object-language. - we all have some logical intuition when we speak, a feeling that allows us to express thoughts without contradiction or to avoid tautology

(ii) the calculative skill of using the formal features of rational language of human thought, applying logical addition and multiplication operations to produce integrations and distributions of subjects and predicates of statements or whole statements into well-ordered symbolic structures that can be transformed into descriptions or symbols generalities or translated into statements that have the character of formal implications in meta-language.

(iii) the science that deals with research, therefore: discovering, forming, transforming, and using ideal thought objects [logical forms] of different complexity and different levels of generality, materially represented in different types of semantic characterization and different hierarchies of structural characterization;

By "thought objects of varying complexity" we mean the logical forms concept, judgment, conclusion, definition, proof, context, theory, theoretical models. By "different level of generality" we mean the range of representation that a logical form can have as a variable within a theory.

Logic is the science within which objects of varying complexity are explored, and therefore logic is the science of hierarchy the characterization of the logical ["true on the basis of form"]. Within logic as well as within mathematics it reigns

[1] hierarchy of complexity of objects under investigation,

[2] hierarchy of languages (notations) by which these objects are characterized (described)

[3] hierarchy of object operation techniques used for this purpose.

(iv) the set of techniques for characterizing the true value of different types of "the logical one" ["true on the basis of form"], some of which are primitive or unconditionally true (unconditioned); some types are characterized as unilaterally conditionally true (conditioned), some types of logical are doubly or bilaterally conditioned in their truthfulness (biconditioned); some are multi-conditioned (multiconditioned-polyvalent)

(v) the scientific tool of natural and social sciences that establish a network of analytical hypotheses on the subject of its interest and deduce from them 
theoretical statements that connect into consistent theoretical units by applying standard and non-standard techniques of quantification, substitution, unification, etc.; or inductive procedures integrate the characterization of the subject of the research, which turns into conclusions; the tool and language with the help of which individual sciences formalize or axiomatize their research and the results of their research - it is logically laid down in deductive systems of formation and transformation, in derivations and procedures of symbolic notation and notation systems. It does not depend on the reference or the extension, it does not depend on the ontology, it is virtual and the variable is only a substitute interpretation

(vi) the artificial programming language of procedures of constructed technical systems based on application of artificial intelligence algorithm, control of degrees of realization of inference, or based on non-monotonic logical operations, primarily a new type of negation (negation-as-failure) [LOGIC PROGRAMMING]

(vii) the philosophical discipline that produces a variable critical and analytical idiom or methods of interpreting and re-interpreting epistemological and ontological assumptions of theory, or that produces the principle of logic as an ideal matrix for identifying and re-identifying the validity of logical principles in any procedure leading to any theoretical model or meaningful description in philosophy.The logical that logic deals with depends on the critical and analytical idiom (ontological, mathematical, pragmatic), i.e. it depends on the choice of ontological and epistemological assumptions of a theory. The logical is contained in the language of theory, in the whole of the statements that a theory formulates in relation to its subject. It depends on the object-related variable, the reference, or the extension.

Here we have listed seven types of characterization of logic, highlighting aspects of the logical that is its subject. Simply put, logic deals with the characterization of (1) thoughts or thought content expressed in (2) statements that are presented (expressed or uttered) in a form in which (3) the existence or non-existence of a state of things or facts is claimed. The ways in which logic deals with these subjects are also different: it reveals valid forms of thought (logical forms), characterizes their type of generality, and finally sets the rules and laws of their formations and transformations into other forms of higher or lower type of generality. Conception (formation and explication of the concept) judgment, inference, proving are only forms of manifestation of logical methods and techniques, correct or incorrect application of logical laws, principles and rules to the stated logical forms in the process of inferential thinking or construction, reconstruction or deconstruction of everyday discourse, scientific theories or philosophical systems. 


\section{Conclusion}

Logical science can be reduced and simplified to formal knowledge of manipulating with concepts, with conceptual relations in statements, with operations on concepts and their properties only because logical forms have a calculative capacity that includes both quantitative and qualitative properties of operations and logical relations. The overall logical science taken in this way is reduced to formal logic (syllogistics, logic of propositions, logic of predicates) to which quantification forms are added.

Ontologically oriented logic (referential model of logic) such as syllogistics rests on a specific complex of three types of identity and three types of predication. Ontologically oriented syllogistics that is partially formalized in apodictic syllogism rests on the concept of truth as correspondence: the conditions of truth of conclusion are given in the premises structure and arrangement of terms, but the conditions of premises truth are given in the extra logical concept of truth of judgements as their correspondence with facts of experience. The meanings of a premise are the meanings of terms that have the role of names of subjects or descriptions for predicative parts.

Symbolic logic (inferential model of logic) requires the complete formalization of the deduction system, either by axiomatization or otherwise, requires formal language (syntax and semantics), requires formal rules of deduction. The conditions for the truthfulness of conclusions and evidence in symbolic logic are the implications that exist in the whole of the conceptual content of thought as its parts. This whole of thought (one statement, atomic or complex) is symbolically represented together with its conditions of truth-implications (conditional). The meanings of symbols are logical objects and symbols have no meaning other than the truth value that is postulated to them (true-false). Symbolic logic drastically changes the concept of identity and replaces it with the concept of equivalence between symbols or signs.

\section{References}

Aristoteles' Metapysik I-II (1978). In griechiesch-deutsch. In ubersetzung von Herman Bonitz. Neu bearbeitete mit Einleitung und Komentar von Horst Sedel. Velix Meiner Verlag, Leipzig.

Aristotle Posterior Analytics. (1997) by Loeb Classical Library.Harvard University Press. 
Aristotle (1987, 1990). "Categories", In Ackrill, J.L. (ed.) A new Aristotle Reader . Oxford: Clarendon Press, pp.5-11.

Bäck, Allan T. (2000). Aristotle's Theory of Predication (Philosophia Antiqua). Brill Academic Publishers.

Boole, G. (1848). The Mathematical Analysis of Logic, being an essay towards a calculus of deductive reasoning. New York: Philosophical Library.

Boole, G. (1854 ). An Investigation of the Laws of Thouths, on which are founded the mathematical theories of logic and probabilities. New York: New York: Philosophical Library.

Carnap, R. (1937). The Logical Syntax of Language. New York: Harcourt, Brace, Carnap, R. (1958). Introduction to Symbolic Logic and its Applications. Dover Publications.

Carnap, R. (1948). Introduction to Semantics. Cambridge, Massachusetts: Harvard University Press.

Dewey, J. (1938). Logic - The Theory of Inquiry. New York: Henry Holt and Company.

Frege, G. (1964). Begriffsschrift und andere Aufsatze. Hildesheim: Olms.

Frege, G. (1967). " Über die Begriffsschrift des Herrn Peano und meine Eigene ", In G. Frege, G.

Frege, G. (1969). "Booles rechnende Logic und meine Begriffsschrift." In Frege, G. Nachgelassene Schriften. Hamburg: Felix Meiner Verlag.

Frege, G. (auth.), Patzig, G. (ed.) (2008). Funktion, Begriff, Bedeutung. Fünf logische Studien. Herausgegeben und eingeleitet von Günther Patzig. Vandenhoeck \& Ruprecht.

Frege. G. (1964). " Uber der Zweck der Begriffsschrift." In: Begriffsscrift und andere Aufsatze. Hildesheim: Olms.

Hilbert, D.(1930). The Principles of Mathematical Logic. New York: Chelsea Publishing Company. 
Hilbert, D. "Axiomatische Denken", In Hilbert (1935, 1970). Gesammelte Abhandlungen. Dritter Band: Analysis. Grundlagen der Mathematik. Physik. Verschiedenes. Berlin: Springer Verlag, pp.146-156.

Ibrulj, N. (1999). Filozofija logike. Sarajevo: Sarajevo Publisching.

Ibrulj, N. (2005). Stoljeće rearanžiranja. Sarajevo: FDT.

Jeffrey, R. C. Burgess, J. P. (2006). Formal Logic. Its Scope and Limits.Hackett Publishing Company, Inc.

Kant, I. (1976). Kritik der reinen Vernunf. Hamaburg: Velix Meiner Verlag.

Kripke. S. (1972, 2001). Naming and Necessity.Cambridge, Harvard: Harvard University Press.

Łukasiewicz, J. (1957). Aristotle's Syllogistic from the Standpoint of Modern Formal Logic. Oxford: Oxford University Press.

Łukasiewicz, J. (1963). Elements of Mathematical Logic.Pergamon Press.

Quine, W.V.O. (1970, 1986). Philosophy of Logic. New York: Prentice-Hall.

Rieger, B. B. (1999): Semiotics and Computational Lingustics. On Semiotic Cognitive Information Processing. In: Zadeh, Lotfi A. / Kacprzyk, Janusz (eds.): Computing with Words in Information / Intelligent Systems I. Foundations [Studies in Fuzziness and Soft Computing 33], Heidelberg, (Physics Verlag), pp.93-118. Dostopno na: http://www.ldv.uni-trier.de.

Russell, B. (1996). Principles of Mathematics. W. W. Norton \& Company.

Scholz, H. (1961). Concise History of Logic. Wisdom Library. New York (Translated from the Geman: Abriss der Geschichte der Logik).

Wittgenstein, L. (2009). Philosophical Investigations (en face German-English edition). Wiley- Blackwell Publishers.

Zadeh, L.A. (1987). From Computing with Numbers to Computing with Words. From Manipulations of Measurements to Manipulation of Perception. https://www.researchgate.net/publication/227112735. 